\title{
Assessing the performance of a Northeast Asia Japan-centered 3-D ionosphere specification technique during the 2015 St. Patrick's day geomagnetic storm
}

\author{
Nicholas Ssessanga ${ }^{1 *}$, Mamoru Yamamoto ${ }^{1}$ and Susumu Saito ${ }^{2}$
}

\begin{abstract}
This paper demonstrates and assesses the capability of the advanced three-dimensional (3-D) ionosphere tomography technique, during severe conditions. The study area is northeast Asia and quasi-Japan-centred. Reconstructions are based on total electron content data from a dense ground-based global navigation satellite system receiver network and parameters from operational ionosondes. We used observations from ionosondes, Swarm satellites and radio occultation $(\mathrm{RO})$ to assess the 3-D picture. Specifically, we focus on St. Patrick's day geomagnetic storm (17-19 March 2015), the most intense in solar cycle 24. During this event, the energy ingested into the ionosphere resulted in Dst and $\mathrm{Kp}$ and reaching values $\sim-223 \mathrm{nT}$ and 8, respectively, and the region of interest, the East Asian sector, was characterized by a $\sim 60 \%$ reduction in electron densities. Results show that the reconstructed densities follow the physical dynamics previously discussed in earlier publications about storm events. Moreover, even when ionosonde data were not available, the technique could still provide a consistent picture of the ionosphere vertical structure. Furthermore, analyses show that there is a profound agreement between the RO profiles/in-situ densities and the reconstructions. Therefore, the technique is a potential candidate for applications that are sensitive to ionospheric corrections.
\end{abstract}

Keywords: Ground-GNSS-STEC tomography, lonosonde data assimilation, Geomagnetic storm

\section{Introduction}

In transionospheric radio communication, central to the precise performance is the ability to understand, characterize, and forecast the distribution of an irregular transiently changing dispersive terrestrial plasma (see for example Jakowski et al. 2011; Kelly et al. 2014; Eastwood et al. 2017; Yasyukevich et al. 2018; Rovira-Garcia et al. 2020). Despite the complexity of this subject, traditionally in the past few years a simplistic horizontal distribution has been suffice, to a certain level of accuracy, to correct

\footnotetext{
*Correspondence: nikizxx@gmail.com

${ }^{1}$ Research Institute for Sustainable Humanosphere, Kyoto University, Uji, Kyoto, Japan

Full list of author information is available at the end of the article
}

for the ionospheric effects on radio signals (e.g., Saito et al. 1998; Jakowski et al. 2012, 2011; Ohashi et al. 2013). The horizontal distribution is mainly deducible from total electron content (TEC), a derivable quantity from abundantly available satellite-ground radio transmissions (Otsuka et al. 2002; Ma and Maruyama 2003). However, as technological systems become more integrated, the demand for high precision on transionospheric signals has increased. Thus, the need for a detailed three-dimensional (3-D) ionosphere picture, for better accuracy, is inevitable. Computerized ionospheric tomography (CIT) is a way to make 3-D (or 2-D) distribution, i.e., an analysis technique to give height dimension from the organized multi-point measurements of TEC. Such advanced CIT is now called ionospheric imaging and is vital in 
radio communication since it provides information on the four-dimensional (time and space) evolution of the electron density structure. An excellent review and history on some of these techniques is found in Bust and Mitchell (2008).

The fidelity of the imaging technique depends on the accuracy of the measurements as well as the temporal and spatial distribution of the data used in the reconstruction. Unfortunately, in most cases, measurements are imperfect and irregular in space and time. Besides, geometry constraints limit the observation information that can be included in the analysis. In return, imaging or tomography analysis (inverse problems) are generally under-determined and ill-posed (Yeh and Raymund 1991; Raymund et al. 1994; Bust and Mitchell 2008). To have a consistent 3-D picture, prior information from other sources such as models is needed. The accuracy of this information and the subject of how to best combine it with measurements has spawned an explosion of research and suggestions (e.g., Fremouw et al. 1992; Howe et al. 1998; Rius et al. 1998; Bust et al. 2000; Tsai et al. 2002; Mitchell and Spencer 2003; Ma et al. 2005; Schmidt et al. 2008; Okoh et al. 2010; Seemala et al. 2014; Ssessanga et al. 2015; Chen et al. 2016; Saito et al. 2017).

To maximize the advantages of imaging techniques, reconstructions are performed on a regional basis; wherein observations are abundant, and computation is tractable under high spatial grid resolution settings. Over the East-Asian sector, an imaging technique has been developed based on a regional network of dense GNSS (global navigation satellite system) receivers and ionosondes (Saito et al. 2017, 2019; Ssessanga et al. 2021). Figure 1 showcases the network and the horizontal resolution settings. The vertical dimension

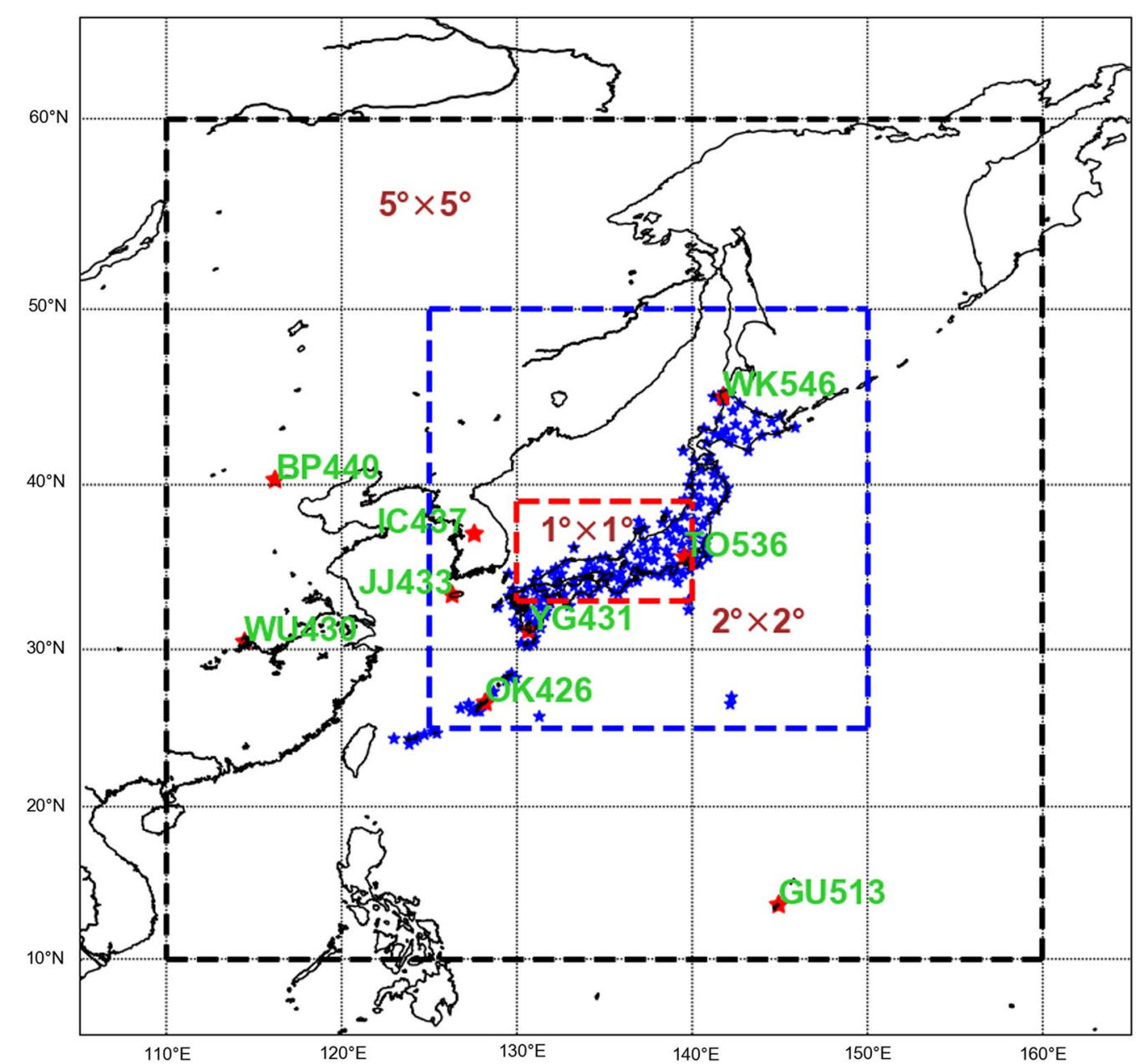

Fig. 1 Image obtained from the works of Ssessanga et al. 2021: a network of GNSS receivers (blue asterisks) and ionosonde stations (solid red stars) used in the analysis. Horizontal boundaries of the different sub-grid regions that compose the overall grid used in computation are marked by solid dashed lines. The sub-grid resolution decreases with increasing distance away from the dense network 
is not illustrated in the picture but extends to a GNSS altitude of $25,000 \mathrm{~km}$ (see Saito et al. 2017). The technique is a two-stage algorithm: First GNSS STEC (slant total electron content) is used to reconstruct the ionosphere electron density field based on constrained leastsquares CIT. Second, to improve the exactness of the reconstructed picture, CIT densities are considered as background in an ionosonde data assimilation technique which assumes that ionosphere electron densities are better described by a log-normal distribution. Saito et al. (2017, 2019) and Ssessanga et al. (2021), have provided the mathematical derivation of this algorithm together with some preliminary results showing that the algorithm performs better than a stand-alone CIT technique. However, the authors did not specifically provide a performance analysis of the algorithm during geomagnetically disturbed conditions. Moreover, a wide spectrum of energy injected into the ionosphere during geomagnetic storms leads to a chaotic and nonlinear ionosphere both in space and time. Although the main phase of a storm may last for a short period, the aftermath effects can last for many days before recovery [Prölss (1995) and Buonsanto (1999)]. Under such deviant conditions, most climate [such as International Reference Ionosphere (IRI)] or physics-based models used in forecasting and nowcasting ionospheric behaviour are rendered insufficient. Therefore, for applications that utilize transionospheric signals, a need for a data-sensitive nearreal-time observation driven algorithm is paramount. The goal of this paper is to show that the technique suggested by Ssessanga et al. 2021, can detect electron density dynamics even during severe storm conditions, and thus a potential candidate for near-real-time ionospheric corrections/applications. All hyperparameters are maintained the same as published in Saito et al. $(2017,2019)$ and Ssessanga et al. (2021). "A brief description of the algorithm" section gives a short mathematical description of the technique. "Analysis of reconstructions during geomagnetic storm conditions" section presents the reconstructions-measurement (ionosonde comparisons) illustrating the ionosphere electron density dynamics in connection to the ingested energy during the geomagnetic storm. It also analyses in detail the reconstructed densities in comparison to independent observations from Swarm satellites and radio occultation. "Summary" Section concludes the article.

\section{A brief description of the algorithm}

Consider a required regional 3-D electron density field state $(\vec{n})$ and a column vector $\vec{Y}$ of observations within the specified grid. Then a cost function to be minimized under constrained least-squares fit is expressed as

$$
J(\vec{n})=\left\|\mathbf{A} \vec{n}-\vec{Y}+\mathbf{A}^{\mathrm{bc}} \vec{n}^{\mathrm{bc}}\right\|^{2}+\lambda\left\|\mathbf{W} \vec{n}+\mathbf{W}^{\mathrm{bc}} \vec{n}^{\mathrm{bc}}\right\|^{2},
$$

and the solution $(\vec{n})$ that minimizes (1) is written as

$$
\vec{n}=\left(\mathbf{A}^{\mathrm{T}} \mathbf{A}+\lambda \mathbf{W}^{\mathrm{T}} \mathbf{W}\right)^{-1}\left(\mathbf{A}^{\mathrm{T}}\left(\vec{Y}+\mathbf{A}^{\mathrm{bc}} \vec{n}^{\mathrm{bc}}\right)-\lambda \mathbf{W}^{\mathrm{T}} \mathbf{W} \vec{n}^{\mathrm{bc}}\right),
$$

where $\mathrm{A}$ is an operator that maps the electron density field state into observation space, $\mathbf{W}$ is a weight matrix based on prior information and restrains the derived electron density from exceeding a certain value (Saito et al. 2017, 2019). Elements superscripted with bc represent boundary conditions obtained from the NeQuick model (Nava et al. 2008) and where $\lambda(>0)$ is a regularization parameter. In the nutshell, the tomography analysis is based on the dense GPS-TEC data with model empirical data normalized to vertical profile peak densities and only used to constraint the solution (see Seemala et al. 2014). We developed a software system on a desktop PC, and realized the real-time tomography analysis from 1-s GEONET absolute TEC data from 200 stations over Japan. The inter-frequency biases (IFBs) of the satellites and the receivers, used in estimating absolute TEC, are estimated hourly based on an algorithm discussed in Ma and Maruyama (2003) and Saito et al. (2017).

Performance of this tomography (Saito et al. 2017, 2019) was generally good, particularly in May-July, but limited when the F-region peak densities (NmF2) appeared below the $\sim 270 \mathrm{~km}$ altitude range in October and November. The discrepancy in performance was attributed to the tomography constraint conditions that were fined tuned based on data covering May-July (Saito et al. 2019).

Ssessanga et al. (2021) developed an advanced version of this tomography by incorporating two more features that provide a more realistic representation of the ionosphere. One is the inclusion of the ionosonde parameters $h^{\prime} \mathrm{F}$ and foF2 from the nearby operational ionosondes. The other is the evaluation of data as logarithmic of the targeted densities; whereby all the elements in random vector $\vec{n}$ are assumed to be drawn from log-normal distributions, and then apply Gaussian statistics by taking the natural logarithm of each element $\left(n_{i}\right)$. That is

$$
x_{i}=\ln \left(n_{i}\right) \text {. }
$$

A new cost function is then formulated as follows:

$$
\begin{aligned}
J(\vec{X})= & \frac{1}{2}[\vec{Y}-\mathbf{A}(\vec{X})]^{T} \mathbf{R}^{-1}[\vec{Y}-\mathbf{A}(\vec{X})] \\
& +\frac{1}{2}\left[\vec{X}-\vec{X}_{b}\right]^{T} \mathbf{B}^{-1}\left[\vec{X}-\vec{X}_{b}\right],
\end{aligned}
$$

where $\vec{X}$ is a row vector comprising the required $\log$ densities $\left(x_{i}\right), \mathbf{R}$ and $\mathbf{B}$ are data and background errors 
covariance matrices, and $\vec{X}_{b}$ is a vector of background log densities from the CIT solution.

The analysis $\log$ density $\vec{X}_{a}$ that minimizes (4), is derived as:

$$
\begin{aligned}
\vec{X}_{a}^{j}= & \vec{X}_{b}+\mathbf{B} \mathbf{A}_{j-1}^{T}\left[\mathbf{R}+\mathbf{A}_{j-1} \mathbf{B} \mathbf{A}_{j-1}^{T}\right]^{-1} \\
& {\left[\vec{Y}-\mathbf{A}\left(\vec{X}_{a}^{j-1}\right)+\mathbf{A}_{j-1}\left[\vec{X}_{a}^{j-1}-\vec{X}_{b}\right]\right], }
\end{aligned}
$$

where $\mathbf{A}_{j-1}$ is a Jacobian evaluated at iteration $j-1$. At optimal, the real densities $n_{i}$ are computed as $10^{\left(i x_{a}^{j}\right)}$; we have taken advantage of $\ln \left(n_{i}\right)=2.303 * \log _{10} n_{i}$ and used a more tractable base 10 . These improvements enhanced the performance of our tomography analysis, with the ability to track the NmF2 below the $270 \mathrm{~km}$ altitude range. Figure 2 shows examples of reconstructed vertical electron density profiles at different ionosonde locations in Japan. Refer to Fig. 1 and Table 1 for the geographic locations and full names of the ionosondes stations. Colours green, blue and red represent the original tomography, improved/modified version, and ionosonde bottomside densities, respectively. In each subplot, the $270 \mathrm{~km}$ baseline is illustrated with a purple horizontal dashed line. Contrary to the original tomography, the modified version displays a distinct ability to vividly follow the measured profiles both vertically and horizontally

\begin{tabular}{|c|c|c|c|c|}
\hline \multicolumn{2}{|c|}{ lonosonde stations } & \multicolumn{2}{|l|}{ Geographic } & \multirow{2}{*}{$\begin{array}{l}\text { Geomagnetic } \\
\text { Latitude ('N) }\end{array}$} \\
\hline Location & Code & Latitude $\left({ }^{\circ} \mathrm{N}\right)$ & Longitude ( $\left.{ }^{\circ} \mathrm{E}\right)$ & \\
\hline Guam & GU513 & 13.62 & 144.86 & 5.79 \\
\hline Okinawa ${ }^{a}$ & OK426 & 26.68 & 128.15 & 17.43 \\
\hline Wuhan & WU430 & 30.50 & 114.40 & 20.71 \\
\hline Yamagawa $^{a}$ & YG431 & 31.20 & 130.62 & 22.06 \\
\hline$J_{e j u^{a}}$ & JЈ433 & 33.43 & 126.30 & 24.4 \\
\hline Kokubunji & TO536 & 35.71 & 139.49 & 27.18 \\
\hline I-Cheon ${ }^{\mathrm{a}}$ & IC437 & 37.14 & 127.54 & 27.80 \\
\hline Beijing & BP440 & 40.30 & 116.20 & 30.53 \\
\hline Wakkanaia & WK546 & 45.16 & 141.75 & 36.75 \\
\hline
\end{tabular}

Table 1 lonosonde stations used in analysis

The arrangement is in ascending geomagnetic latitude

a Indicates stations located within the sub-grid region of high-resolution marked out in blue dash lines in Fig. 1

at different ionosonde latitude-longitude locations. This is effective adaptiveness, and in the sequel, we further examine the penitential of the modified tomography under extremely chaotic ionosphere conditions. In fact, this work is part of a pre-analysis of the modified tomography version before advancing to a near-real-time online version (https://www.enri.go.jp/cnspub/tomo3/plott ing.html).
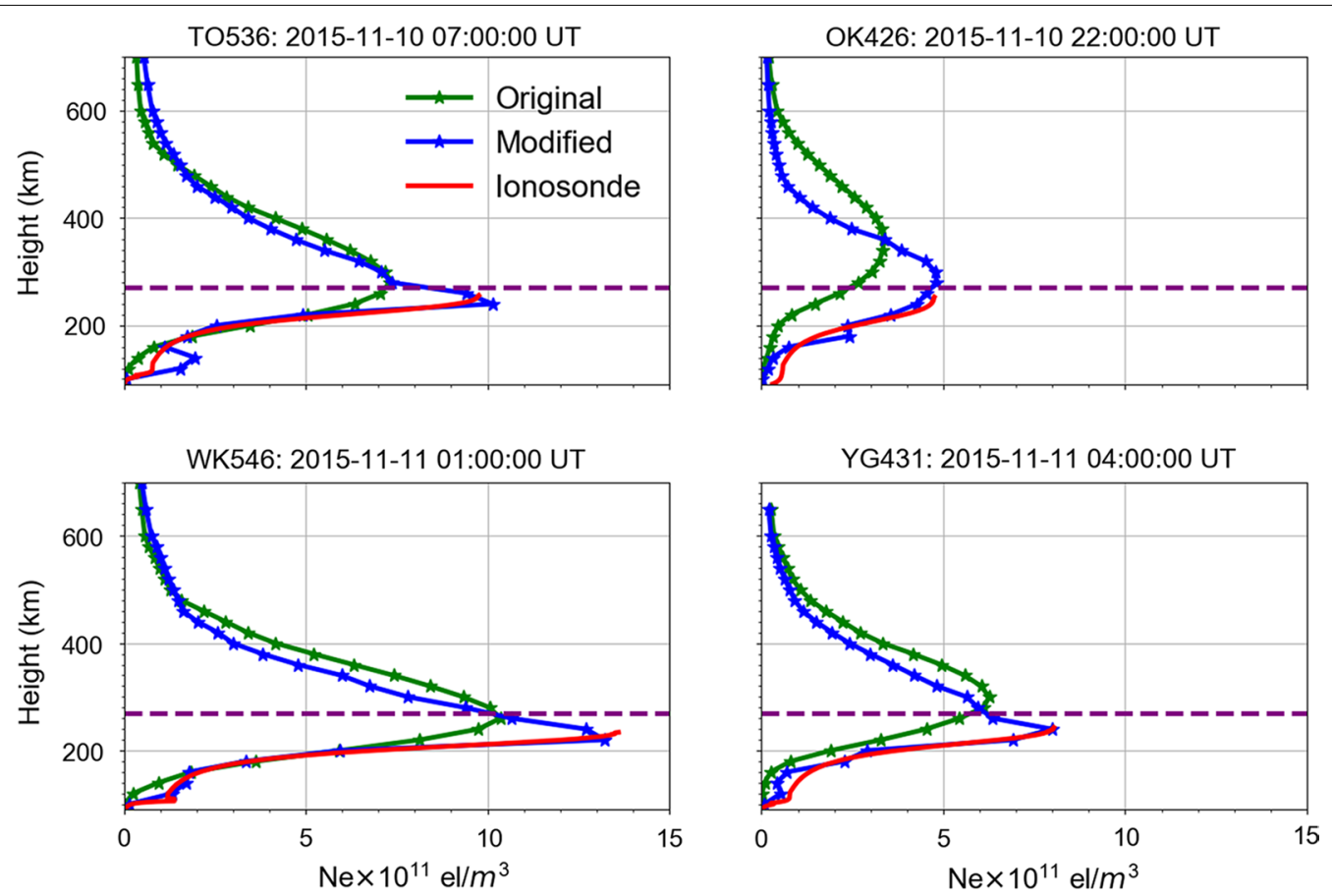

Fig. 2 Examples of density profiles reconstructed at different ionosonde locations in Japan. The time stamps are indicated at the top of each subplot. The original tomography densities without the assimilation complexity are shown in green. Eminent is the robustness of the modified version (blue) to track the ionosonde measured (red) densities below the $270 \mathrm{~km}$ altitude range (purple line) 


\section{Analysis of reconstructions during geomagnetic storm conditions}

The geomagnetic storm analysed occurred on St. Patrick's day [day of year (DOY) 076-077] in 2015 and was among the most intense storms in the 24th solar cycle (Astafyeva et al. 2015). We reconstruct the ionosphere vertical structure during this period (at a resolution of $15 \mathrm{~min}$ ) and briefly analyse the variations in reference to the ionosphere disturbance indicator, Dst index. Specifically, the vertical structure is analysed at ionosonde locations for easy comparison with ground ionosonde observations. In-situ densities from the Swarm constellation and radio occultation density profiles are also utilized to assess the reconstructed F-region topside densities. Throughout the analysis, international reference ionosphere (IRI-2016, Bilitza et al. 2017) model densities are also presented as a form of reference. However, it should be noted that the IRI model is a climatological model for average values, so might not be the best candidate for performance evaluation against ionosphere tomography models that include weather.

\section{Storm chronological highlights}

A coronal mass ejection (CME) was observed erupting between $\sim$ 00:30 UT and 00:04 UT on DOY 074 and was predicted to encounter the Earth's magnetosphere on DOY 076. Figure 3 illustrates how the abundant energy injected into the magnetosphere-ionosphere system perturbed the terrestrial geomagnetic field leading to a Dst (Kp index) minimum (maximum) recording of approximately $-223 \mathrm{nT}(8)$. Kp as blue is scaled on the right and Dst as black is scaled on the left. Dashed vertical lines indicate the main events of the storm. Both indices can be obtained from the World Data Center for Geomagnetism, Kyoto http://wdc.kugi.kyoto-u.ac.jp/ (Nose et al. 2015) or https://omniweb.gsfc.nasa.gov/form/dx1.html.

Before DOY 076, the geomagnetic indices Kp and Dst were relatively stable with magnitudes below 4 and $50 \mathrm{nT}$, respectively. On DOY 076, at 04:45 UT (storm sudden commencement, SSC), the CME hit the Earth, leading to an increase in Dst. On the same day, at 07:30 UT the main phase of the storm commenced and the Dst decreased to a local minimum of $\sim-80 \mathrm{nT}$. During this period the interplanetary magnetic field (IMF) Bz component was reported to have turned southward (see bottom panel in Fig. 3 and also refer to Cherniak et al. 2015). From about 9:30 UT to

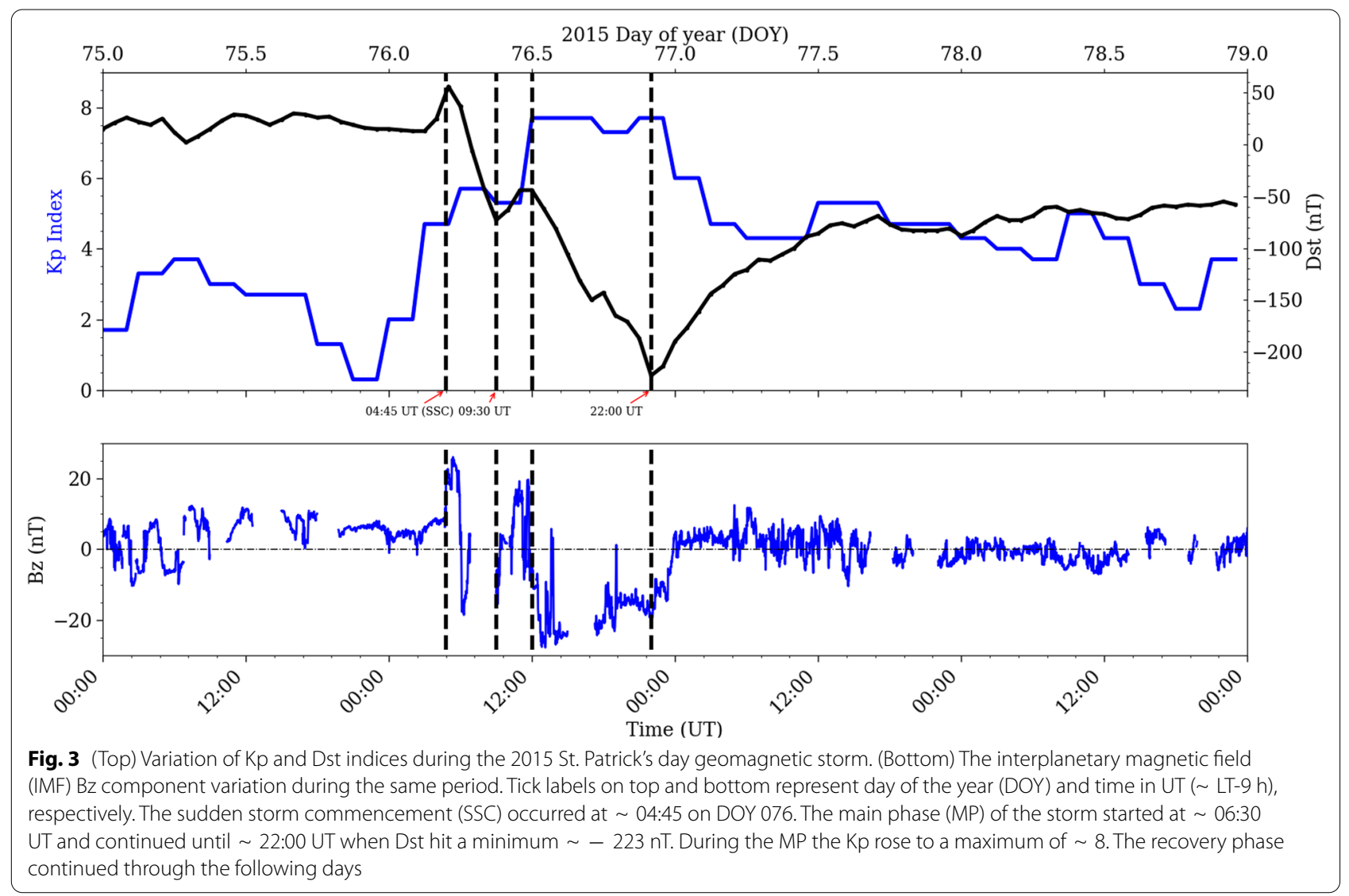


12:20 UT there was a short-lived recovery in the Dst index to $-50 \mathrm{nT}$; expected to be due to the IMF Bz component turning Northward (Astafyeva et al. 2015). From 12:20 UT the Dst continued with a gradually decreasing trend reaching a global minimum $(-223 \mathrm{nT})$ at $\sim 22: 00 \mathrm{UT}$ on DOY 076. The recovery phase continued through the following days with the Kp index ranging below 6 .

\section{Analysis of reconstructions at ionosonde locations}

In Fig. 4 we have generated images from a time series of vertical profiles corresponding to locations of ionosondes within the high-resolution sub-grid region marked out in blue dashed lines in Fig. 1; Ssessanga et al. 2021 found that a coarse horizontal spacing $\left(5^{\circ} \times 5^{\circ}\right)$ in the outside subgrid might not reflect a true representation of the ionospheric state and dynamics, particularly at the low latitudes where the ionosphere is expected to have steep gradients. Consequently, results presented here are limited to the region where we expect a coherent and consistent reconstruction. Refer to Table 1 for the locations, four character code names, geographic coordinates and geomagnetic latitude of each ionosonde used in analysis. Ionosondes located in the region of high-resolution are labeled with an "a" superscript.

The images in Fig. 4 are arranged in accordance with increasing ionosonde geomagnetic latitude. The top, middle and bottom panels represent the IRI-2016 model, assimilated CIT, and observations from ionosondes, respectively. Tick labels at the top of each panel show days of the year while those at the bottom show time in UT (the East Asian sector local time (LT) is $\sim 9 \mathrm{~h}$ ahead of UT). Preferably, IRI and reconstructed densities were converted to frequency $(\mathrm{MHz})$ for easy comparison with ionosonde measurements. The colour scale of the frequency in each panel is given in the far right bottom corner.

In each image plate: for clarity, the altitude range is limited to the region of uttermost interest (F-region $\sim 200-600 \mathrm{~km}$ ). Superimposed is the Dst index (ordinate axis on the right) in order to track the response of the ionosphere during the different storm dynamics. As indicated earlier, dashed vertical lines indicate the main events of the storm. The horizontal dashed line at $300 \mathrm{~km}$ is included as a baseline to vividly track the uplift of the plasma density. The timealtitude variation of the peak-density is represented by the purple solid-asterisk line. In the reconstructed, and ionosonde images, white spaces indicate periods when GPS-ground receiver ray links and ionosonde observations did not exist or intersect that particular location. At a particular time-stamp, if there exist any data gaps within the $200-500 \mathrm{~km}$ altitude range, the peak density is not determined.

Throughout the selected analysis period, at all stations, the IRI model only shows the general diurnal variation of the $\mathrm{F}$ region without detailed features. This is expected since IRI is a climatological model that represents monthly averages of terrestrial plasma densities/ frequencies (Bilitza et al. 2017). Consequently, the IRI model performance is usually found lacking when ionosphere underlying driving mechanisms are deviant from the general trend.

Contrary to IRI, reconstructed results reflect changes in the plasma frequency following variations in the Dst index as detailed: the onset of the storm occurred when the East Asian sector was on the day-side. Compared to reconstructed densities on the day before the storm (DOY 075); nearly just after the SSC, at OK426 station that is located geomagnetically in low latitudes, there is a slight noticeable instantaneous uplift (marked with a grey arrow) of the peak densities to altitudes above the $300 \mathrm{~km}$ baseline. The uplift reduces in amplitude towards the high latitudes (not noticeable at TO536) and is most probably due to geomagnetic storm induced eastward prompt penetration electric fields (PPEF), which end up modifying the equatorial and low-latitude ionospheric phenomenology (Maruyama et al. 2004).

Approximately two hours after the SSC, there was a slight increase in F region plasma densities $(\sim 280-$ $340 \mathrm{~km}$ ) particularly at stations located near the equatorial anomaly (OK426 and JJ433). In addition, there was a well defined wavy modulation of the peak density altitude at mid-latitude stations (JJ433, TO536 and IC437). The $\sim 2$-h delay falls within the time frame the traveling atmospheric disturbance (TAD) created at high latitudes during geomagnetic storms, would take to propagate to the mid and low latitudes (for example see the works of Shiokawa et al. 2003 and references therein). Therefore, low latitude ionisation and wavy modulation of the midlatitude $\mathrm{F}$ region could be related to an equatorwards propagating surge and plasma density enhancements in equatorial ionization anomaly (EIA) crests, following day-side PPEF.

\footnotetext{
(See figure on next page.)

Fig. 4 lonosphere vertical structure at 5 ionosonde locations within the grid, during the 2015 St. Patrick's Day geomagnetic storm. Top, middle and bottom panels represent IRI-2016, reconstructed, and ionosonde observations, receptively. Stations in each panel are arranged in ascending geomagnetic latitude. Tick labels on top and bottom of each panel represent day of the year (DOY) and time in UT ( LT-9 h), respectively. Scaled on the right of each image is Dst index, represented by the solid black line. Vertical dashed lines indicate the main events of the storm. In the IRI and reconstructed images, the purple solid-asterisk line shows the time variation of the hmF2 parameter at that ionosonde location
} 


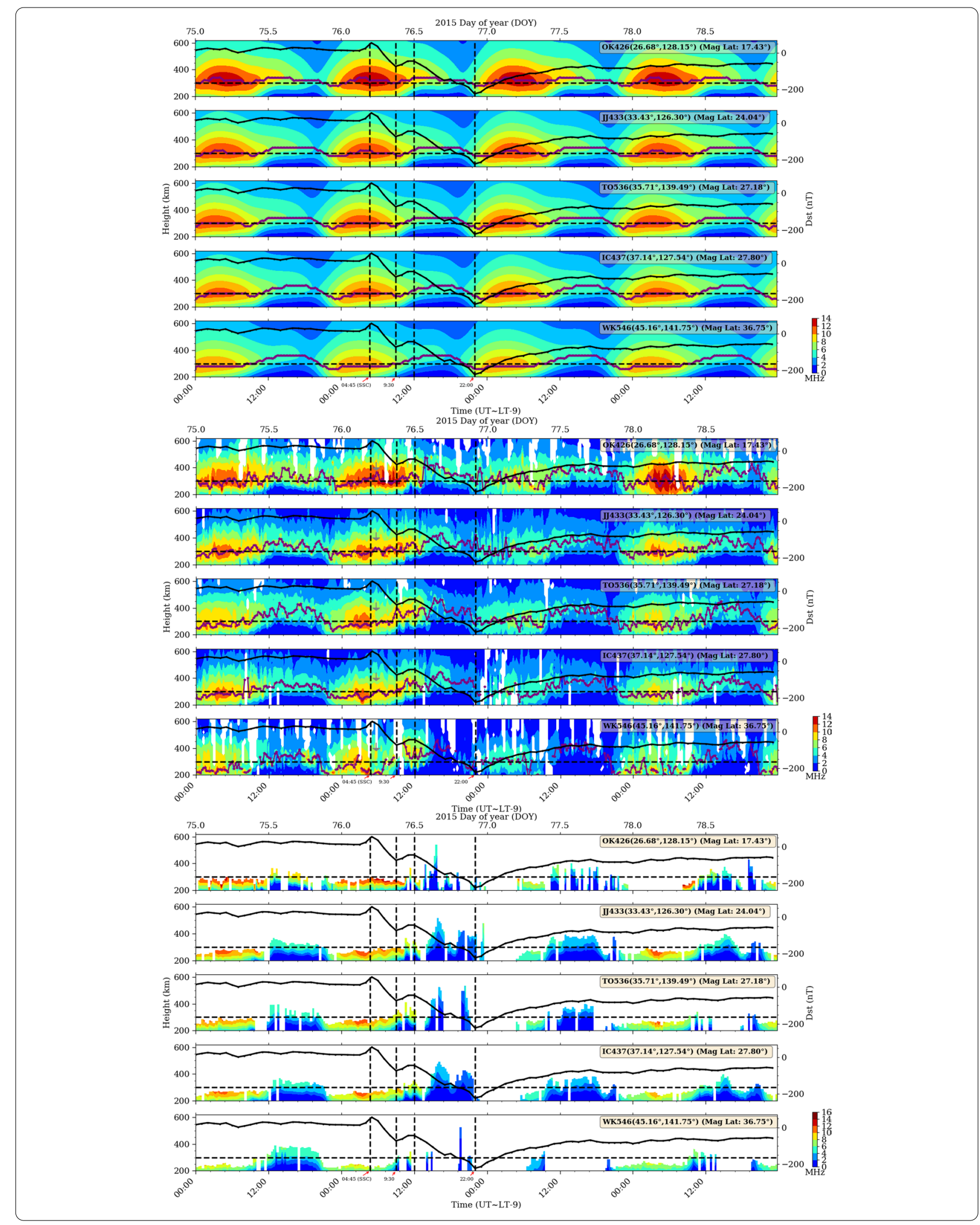


By the time the East Asian sector enters the night side $(\sim 10: 30 \mathrm{UT})$, there is a short-lived recovery in the plasma frequency between 10:30 and 12:30 UT. Thereafter ( 12:30-24:00 UT), specifically at stations located in the mid-latitudes (JJ433, TO536 and IC437) and towards high latitudes (WK546), the plasma is uplifted to high altitudes $(\sim 500 \mathrm{~km})$, gradually falls to $\sim 320 \mathrm{~km}$, rises again to about $\sim 380 \mathrm{~km}$ and finally settles to an average altitude of $\sim 300 \mathrm{~km}$. Through this whole process, at all stations, the initial daytime plasma enhancements decrease gradually (to values nearly below $4 \mathrm{MHz}$ ), following the Dst index which hits a minimum at about 22:00 UT. The decrease in F-region densities accompanied by descent in altitude of the peak densities could be attributed to an equatorward wind surge and the nightside westward PPEF which has opposite effects (reduction in EIA ionisation) in reference to day-side PPEF.

On the day after the storm (DOY 077), at all stations, the plasma density (frequency) remained nearly $\sim 60 \%$ below the values observed on the day before the storm. Interesting to note through this period, is the total or partial absence of data at all ionosonde stations. From the reconstructions, it is clear that these data gaps were due to a significant decrease in the $F$ region plasma frequency $(<4 \mathrm{MHz})$ such that the ionosonde could not detect the reflected echoes. This is a well-known/typical negative ionospheric response following a major geomagnetic storm (e.g., Fuller-Rowell et al. 1994; Prölss 1995; Tsagouri et al. 2000). A possible explanation for the intense plasma reduction is that the substorm activity on DOY 076 generated a composition bulge that entered the Asian sector, and persisted through the next day (DOY 077). In fact, Astafyeva et al. (2015) and Nava et al. (2016), analysed the thermospheric column integrated $\mathrm{O} / \mathrm{N} 2$ ratio changes measured by the GUVI (global ultraviolet imager) instrument onboard the TIMED (thermosphere, ionosphere, mesosphere energetics and dynamics) satellite during the same geomagnetic storm (DOY 076-078, 2015), and found that the Asian sector had significant composition changes that could have led to the negative ionosphere response.

Latitudinal wise, stations towards the high latitudes (WK546) exhibit the highest reduction in plasma density. This enormous reduction in F plasma densities led to an increase in slab thickness, which is seen to increase polewards (extending $>300 \mathrm{~km}$ in altitude), and most pronounced during the evening of DOY 076 and the early hours of DOY 077. Indeed, different studies have already shown that the slab thickness is dependent on diurnal, annual, latitudinal and storm-time variations [see Stankov and Warnant, (2009), and references therein]. In the longitudinal perspective, stations TO536 and IC4337 that are almost on the same geomagnetic latitude (the difference is $\sim 1^{\circ}$ ) show that the negative storm effect was greater on the Eastern side.

On the third day after the storm (DOY 078), except for OK426, all stations maintain a slow (<6 MHz) gradual recovery towards the normal plasma frequency values observed during the quiet period. Nava et al. (2016) analysed the same storm and illustrated that the recovery process lasted more than 7 days. At OK426, reconstructions indicate that the low-latitudes had an undulating peak, accompanied by reinforced ionisation covering altitudes $\sim 200-420 \mathrm{~km}$. Surprisingly, these effects do not extend to mid-latitudes (see reconstructions at JJ433, TO536 and IC437). Nava et al. (2016) also generated regional TEC maps corresponding to periods, before, during and after the St. Patrick's day storm. Over the Asian sector, on the day after the storm, ionization was confined at low latitudes near the equator, and it almost disappeared at middle latitudes. This characteristic is typical of westward zonal electric field penetration during disturbance dynamo (DD) when EIA is inhibited. Nonetheless, this ambiguous or peculiar behaviour may be related to other post-storm effects that might require further investigation (also see Kutiev et al. 2006).

GPS and ionosonde: The significance of complementing GPS with ionosonde data is well illustrated at most stations; we can reconstruct the full extent of $\mathrm{F}$ region plasma structure beyond the bottomside limitations of the ionosondes. Moreover, as noted earlier, at points where the ionosondes failed to record any echoes due to the low plasma electron content, our technique was still able to provide reasonable plasma content estimations. This is a crucial result particularly for applications that utilize transionospheric HF (high frequency) signals.

\section{Comparison with Swarm densities}

In-situ densities offer a good test of accuracy since they represent a specific point in space (ionosphere) at a particular time. The Swarm constellation consists of three identical polar-orbiting satellites that fly at two different altitudes $\leq 460 \mathrm{~km}$ [Alpha (A) and Charlie (C)] and $\leq 530 \mathrm{~km}$ [Bravo (B)]. Each satellite has a Langmuir Probe that facilitates the measurement of in-situ densities. Part of the Swarm density results presented here are already presented in Ssessanga et al. 2021 (as preliminary results) to showcase the performance of the technique. We will add more analysis plots to cover the morning and evening sectors of the analysed period. The data used in the analysis are Level $1 \mathrm{~b}$ electron density measurements at a $2 \mathrm{~Hz}$ rate, accessible at $\mathrm{ftp}$ ://swarm-diss.eo.esa.int. For a further review on Swarm data see, for example, Olsen et al. (2013).

In Fig. 5, time profiles of Swarm in-situ densities (red) are plotted alongside densities from our reconstructions 


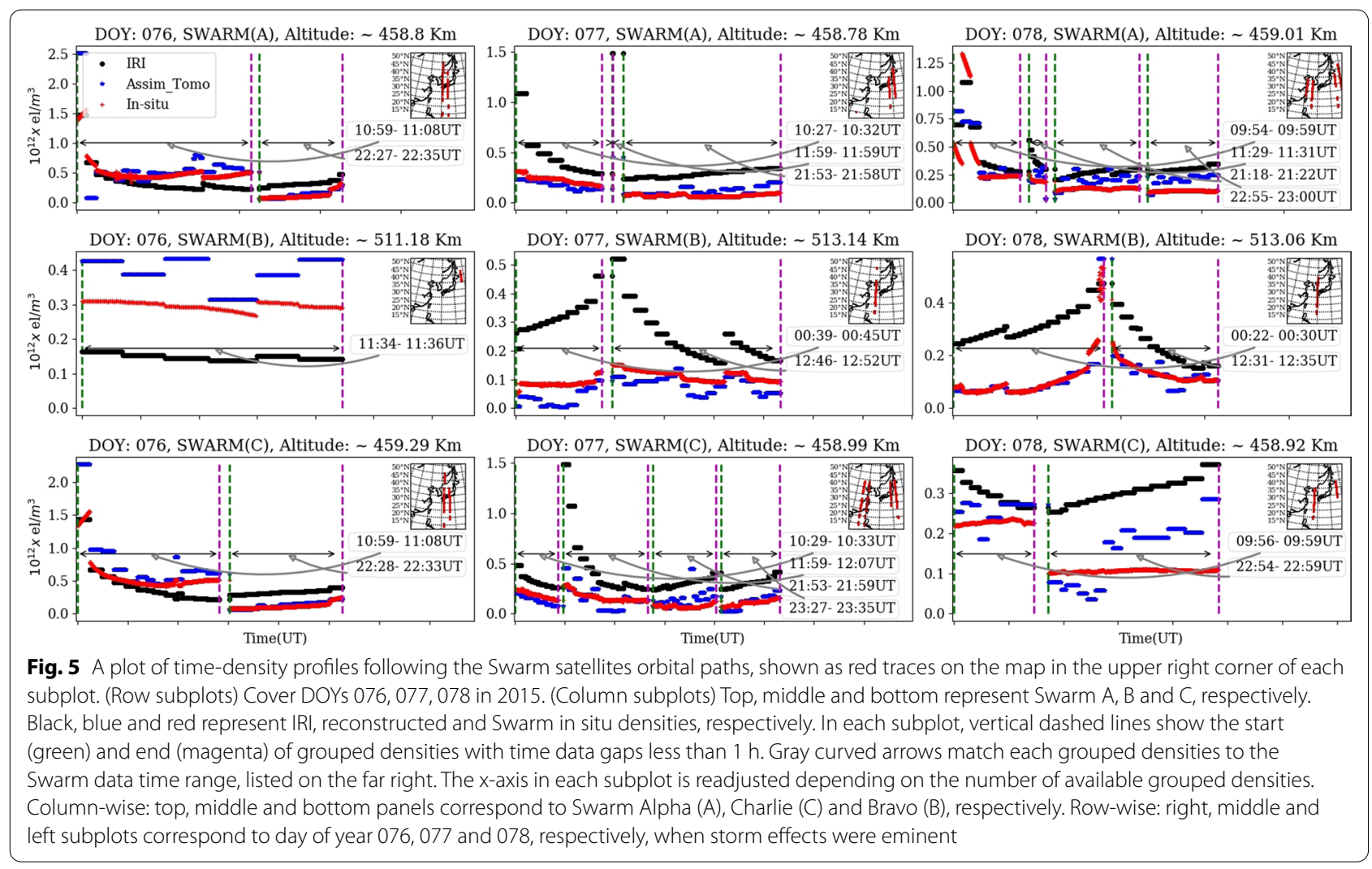

(blue) and IRI model (black). The top, middle and bottom rows of subplots correspond to satellites A, B and C, respectively. Each row of subplots covers three DOYs (076, 077 and 078) during which St. Patrick's day storm effects were most evident. In each subplot, the geographic traces of the Swarm satellite during that particular period are marked red on the map in the upper right corner. Gaps in the traces indicate periods when either in-situ measurements or density reconstructions were not available for analysis. To match our low time resolution $(15 \mathrm{~min}$ ) reconstructions with in-situ measurements, the ionosphere was assumed to remain stationary under a period of $10 \mathrm{~min}$. Then, all in-situ measurements within this window were mapped onto the nearest grid altitude plane within $10 \mathrm{~km}$ to the satellite orbital altitude. The vertical dashed lines in each subplot indicate the start (green) and end (magenta) of grouped densities, in which the time data gaps are less than 1-h. The corresponding Swarm satellite time coverage of each grouped densities is indicated on the far right below the map. The $\mathrm{x}$-axis in each subplot is not linear but rather readjusted depending on the available grouped densities within the day. The middle subplots corresponding to Swarm A and B are essentially a replot from Ssessanga et al. (2021), except we added more observation data points.
In all subplots, the agreement between the reconstructed and in-situ densities is generally good. IRI on the other side exhibits a poor estimation of the densities. Also noticeable is that due to differences in orbital altitudes, there is a slight difference in the level of electron density distributions observed by satellites (A, $\mathrm{C})$ and $\mathrm{B}$. The difference between in-situ and reconstructed densities is on average less than $0.2 \times 10^{12} \mathrm{el} /$ $\mathrm{m}^{3}$. This result offers confidence in the reconstructed topside F-region density structure, which is not attainable while using ground-based instruments such as ionosondes. A point of concern could arise from the poor density reconstructions at the awake of profiles in time range 9:00-11:00 UT (corresponding to satellites $A$ and $C$ on DOY 076 and 077). During this period Swarm A/C traces fall within or near the equatorial latitudes. Ssessanga et al. 2021, ascribed this to a poor grid specification over these latitudes. That is to say, the equatorial ionization anomaly region exhibits steep latitudinal densities gradients, yet, the currently utilized grid assumes a coarse horizontal spacing $\left(5^{\circ} \times 5^{\circ}\right)$ over this region [refer to Fig. 1 and Saito et al. $(2017 ; 2019)$ ], hence reconstructions would not reflect the true ionospheric state and dynamics.

If we follow the traces of Swarm A and C, we observe that on DOY 076 when the storm 


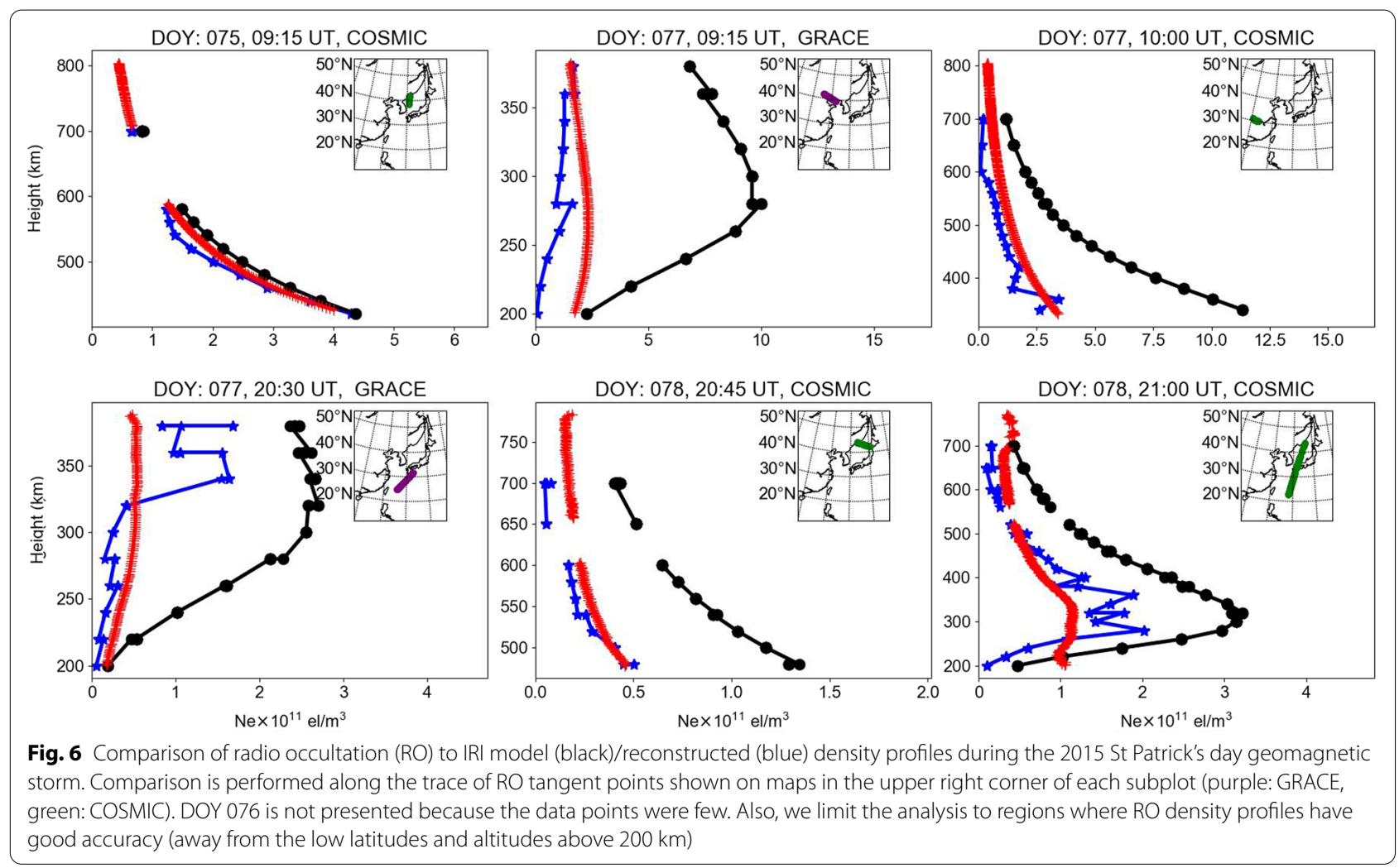

commences $(\sim 10: 00-12: 00 \mathrm{UT})$ the topside densities range $0.5 \sim 2 \times 10^{12} \mathrm{el} / \mathrm{m}^{3}$. On the day that follows, during the same period, when the negative storm effects are dominant, we observe that the densities remain nearly below $0.25 \times 10^{12} \mathrm{el} / \mathrm{m}^{3}(\sim 50 \%$ of the densities on DOY 076). The reduction in plasma densities is also observed at Swarm B altitudes and is maintained throughout the late hours of DOY 077. This result is consistent with the density reductions that were observed in the middle and bottom panels of Fig. 5.

On DOY 078, when the F-region topside densities start returning to normal, the reconstructed densities relatively track well the in-situ measurements, but with a better performance at Swarm B altitudes. The discrepancy in performance may be related to the altitude level; Swarm (A and C) orbit at a lower altitude $(\leq 460 \mathrm{~km})$ than $\mathrm{B}$, and at such altitudes the plasma densities are more likely to be influenced by different nonlinear dynamical forces during the storm period, hence making the reconstruction acute. Certainly, the local time $(\sim \mathrm{UT}+9)$ difference in Swarm B and A/C observations (different ionisation levels) might also influence the results. Nevertheless, the reconstructed densities still outperform the IRI model estimations.

\section{Comparison with radio occultation (RO)}

In Fig. 6, a set of RO electron density profiles (red) from COSMIC (constellation observing system for meteorology, climate, and ionosphere; orbital altitude $\sim 800 \mathrm{~km}$ ) and GRACE (gravity recovery and climate experiment; orbital altitude $\sim 490 \mathrm{~km}$ ) constellations are plotted together with profiles from assimilated tomography (blue) and IRI (black) during the analysed period. RO data are accessible in level 2 format at https://cdaacwww.cosmic.ucar.edu/cdaac/. Comparison is limited to reconstructions away from the low latitudes and above the $200 \mathrm{~km}$ altitude mark, where $\mathrm{RO}$ density profiles are expected to have the best accuracy. That is to say, $\mathrm{RO}$ density profiles are an inversion of $\mathrm{RO}$ total electron content (ROTEC) using the so-called inverse Abel transform that assumes spherical symmetry in the ionosphere: For the most part, profiles from Abel transform have good accuracy, with the exception of the E-region (where rays have asymmetric contributions from the $\mathrm{F}$ region portions of the rays), and low latitudes (where large density gradients exist, Garcia-Fernandez et al. 2003; Wu et al. 2009; Yue et al. 2010). Rather than comparing the RO density profiles to a specific vertical profile within the grid, the comparison is performed at the location of tangent points (which contribute the most density along the RO ray path) shown on the maps in the top right corner 
of each subplot. Purple and green represent GRACE and COSMIC, respectively. Gaps in the profiles indicate instances when assimilated tomography reconstructions were not available. Fortunately, during the analysed period the GRACE constellation covered the $\sim 200$ $400 \mathrm{~km}$ range, whereas COSMIC mostly covered the topside $\sim 400-700 \mathrm{~km}$. This snip view gives us a chance to nearly observe and analyse the capabilities of the assimilated tomography in specifying the electron density field both in time and space (horizontally and vertically).

On the DOY 075 (top left corner subplot) before the storm, both assimilated tomography and IRI have a good estimation of the topside structure. However, on days that follow, assimilated tomography and RO profiles show a dramatic decrease in electron densities consequent to the geomagnetic storm. By contrast, the IRI model maintains a high-density output, with the largest deviation from the truth in the $200-400 \mathrm{~km}$ altitude range. This result is important because it gives a sample of what might be expected in applications that use models to correct for ionospheric effects during severe conditions.

Despite the variability, reconstructed profiles on average adequately track the $\mathrm{RO}$ densities at all height ranges. Surprisingly, a combination of ionosonde densities and ground-based GNSS TEC is adequate to reconstruct a reliable topside structure $(\sim 400-700 \mathrm{~km})$. Nonetheless, the noisy structure of some of the profiles motivates our suggestion in future to integrate RO data (both TEC and electron density profiles) in the analysis to further constrain the vertical structure.

Results presented in this study can be placed in context with previous performance analyses of the tomography technique during the early stages of development. In this sense, our work is a complement to studies by Seemala et al. 2014; Saito et al. 2017, 2019; Ssessanga et al. 2021, who have already analysed the tomography reconstructions during the quiet period and found the technique to have good fidelity. Therefore, the technique seems fairly robust in handling different ionospheric conditions.

\section{Summary}

The material presented here has offered an insight into the ability of the tomography ionosonde data assimilated technique to characterize ionosphere plasma densities even under severe ionosphere conditions. The results clearly demonstrate that the proposed algorithm is a good candidate for a better specification of the regional 3-D ionosphere electron density field; reconstructed electron densities reflect changes following the energy sink into the ionosphere system during a geomagnetic storm.

Moreover, the reconstructed densities are comparable to observations covering both bottom (ground-based ionosonde) and topside (space-borne satellites) ionosphere.

Therefore, for a coherent 3-D ionosphere picture a joint use of both ground GNSS data and bottomside ground-based ionosondes should be emphasized. However, a more rigorous analysis should be performed to further restrain the variability in the reconstructed vertical structure. The introduction of RO data would significantly contribute to the structure stability. Indeed, then it would be of interest to extend our analysis to explore and quantify the impact of the plasmasphere on the stability/fidelity of the whole ionosphere 3-D structure.

\section{Abbreviations}

RO: Radio occultation; GNSS: Global navigation satellite system; GPS: Global positioning satellite system; TEC: Total electron content; STEC: Slant total electron content; CIT: Computerized ionosphere tomography; D: Threedimensional; DOY: Day of year; IRI: International reference ionosphere; CME: Coronal mass ejection; UT: Universal time; LT: Local time; IMF: Interplanetary magnetic field; SSC: Storm sudden commencement; MP: Main phase; PPEF: Prompt penetration electric fields; TAD: Traveling atmospheric disturbance; EIA: Equatorial ionization anomaly; GUVI: Global ultraviolet imager; TIMED: Thermosphere, ionosphere, mesosphere energetics and dynamics; HF: High frequency; COSMIC: Constellation observing system for meteorology, climate, and ionosphere; GRACE: Gravity recovery and climate experiment.

\section{Acknowledgements}

GNSS data from GEONET were provided by the Geospatial Information Authority of Japan.

\section{Authors' contributions}

SN conducted the research. SS and YM contributed to the algorithm design. All authors read and approved the final manuscript.

\section{Funding}

This work is supported by the Japan Society for the Promotion of Science (JSPS) KAKENHI Grant Numbers 19F19031 and 20H00197.

\section{Availability of data and materials}

The GNSS data can be obtained or accessed at National Geographic Information Institute (NGll, http://www.ngii.go.kr/kor/main/main.do?rbsldx=1) and upon request from Geospatial Information Authority of Japan (GSI). The ionosonde data are also accessible at http://wdc.nict.go.jp/IONO/HP2009/ISDJ/ manual_txt-E.html and ftp://ftp.ngdc.noaa.gov/ionosonde/data/. SWARM data are publicly accessible at ftp://swarm-diss.eo.esa.int. The ionospheric electron density radio occultation observation data were downloaded from https:// cdaac-www.cosmic.ucar.edu/cdaac/. Geomagnetic indices were obtained from http://wdc.kugi.kyoto-u.ac.jp and Interplanetary magnetic field data from https://omniweb.gsfc.nasa.gov.

\section{Declarations}

Competing interests

The authors declare that they have no competing interests.

\section{Author details}

${ }^{1}$ Research Institute for Sustainable Humanosphere, Kyoto University, Uji, Kyoto, Japan. ${ }^{2}$ Electronic Navigation Research Institute, National Institute of Maritime, Port, and Aviation Technology, Tokyo, Japan.

Received: 1 March 2021 Accepted: 26 May 2021

Published online: 09 June 2021 


\section{References}

Astafyeva E, Zakharenkova I, Förster M (2015) lonospheric response to the 2015 St. Patrick's Day storm: a global multi-instrumental overview. J Geophys Res Space Phys 12010:9023-9037. https://doi.org/10.1002/ 2015JA021629

Bilitza D, Altadill D, Truhlik V, Shubin V, Galkin I, Reinisch B, Huang X (2017) International reference ionosphere 2016: from ionospheric climate to real-time weather predictions. Space Weather 15(2):418-429. https://doi. org/10.1002/2016SW001593

Buonsanto MJ (1999) lonospheric storms — a review. Space Sci Rev 88(3):563601. https://doi.org/10.1023/A:1005107532631

Bust GS, Mitchell CN (2008) History, current state, and future directions of ionospheric imaging. Rev Geophys. https://doi.org/10.1029/2006RG0002 12

Bust GS, Coco D, Makela JJ (2000) Combined ionospheric campaign 1: ionospheric tomography and GPS total electron count (TEC) depletions. Geophys Res Lett 27(18):2849-2852. https://doi.org/10.1029/2000GL000053

Chen CH, Saito A, Lin CH, Yamamoto M, Suzuki S, Seemala GK (2016) Medium-scale traveling ionospheric disturbances by three-dimensional ionospheric GPS tomography. Earth Planets Space 68:32. https://doi.org/ 10.1186/s40623-016-0412-6

Cherniak I, Zakharenkova I, Redmon RJ (2015) Dynamics of the high-latitude ionospheric irregularities during the 17 March 2015 St. Patrick's Day storm: ground-based GPS measurements. Space Weather 13(9):585-597

Eastwood JP, Biffis E, Hapgood MA, Green L, Bisi MM, Bentley RD, Wicks R, McKinnell LA, Gibbs M, Burnett C (2017) The economic impact of space weather: where do we stand? Risk Anal 37(2):206-218. https://doi.org/10. 1111/risa.12765

Fremouw EJ, Secan JA, Howe BM (1992) Application of stochastic inverse theory to ionospheric tomography. Radio Sci 27(5):721-732. https://doi. org/10.1029/92RS00515

Fuller-Rowell T, Codrescu M, Moffffett R, Quegan S (1994) Response of the thermosphere and ionosphere to geomagnetic storms. J Geophys Res Space Phys 99(A3):3893-3914. https://doi.org/10.1029/93JA02015

Garcia-Fernandez M, Hernandez-Pajares M, Juan M, Sanz J (2003) Improvement of ionospheric electron density estimation with GPSMET occultations using Abel inversion and VTEC information. J Geophys Res Space Phys 108(A9):1338. https://doi.org/10.1029/2003JA009952

Howe BM, Runciman K, Secan JA (1998) Tomography of the ionosphere: four-dimensional simulations. Radio Sci 33(1):109-128. https://doi.org/10. 1029/97RS02615

Jakowski N, Mayer C, Hoque MM, Wilken V (2011) Total electron content models and their use in ionosphere monitoring. Radio Sci. https://doi.org/10. 1029/2010RS004620

Jakowski N, Béniguel Y, De Franceschi G, Pajares MH, Jacobsen KS, Stanislawska I, Tomasik L, Warnant R, Wautelet G (2012) Monitoring, tracking and forecasting ionospheric perturbations using GNSS techniques. J Space Weather Space Clim 2:A22. https://doi.org/10.1051/swsc/2012022

Kelly MA, Comberiate JM, Miller ES, Paxton LJ (2014) Progress toward forecasting of space weather effects on UHF SATCOM after Operation Anaconda. Space Weather 12(10):601-611. https://doi.org/10.1002/2014SW001081

Kutiev I, Otsuka Y, Saito A, Watanabe S (2006) GPS observations of post-storm TEC enhancements at low latitudes. Earth Planets Space 58(11):1479_ 1486. https://doi.org/10.1186/BF03352647

Ma G, Maruyama T (2003) Derivation of TEC and estimation of instrumental biases from GEONET in Japan. Ann Geophys 21(10):2083-2093. https:// doi.org/10.5194/angeo-21-2083-2003

Ma XF, Maruyama T, Ma G, Takeda T (2005) Three-dimensional ionospheric tomography using observation data of GPS ground receivers and ionosonde by neural network. J Geophys Res Space Phys 110:A5. https://doi. org/10.1029/2004JA010797

Maruyama T, Ma G, Nakamura M (2004) Signature of TEC storm on 6 November 2001 derived from dense GPS receiver network and ionosonde chain over Japan. J Geophys Res 109:A10302. https://doi.org/10.1029/2004J A010451

Mitchell CN, Spencer PS (2003) A three-dimensional time-dependent algorithm for ionospheric imaging using GPS. Ann Geophys 46(4):687-696. https://doi.org/10.4401/ag-4373

Nava B, Coisson P, Radicella SM (2008) A new version of the NeQuick ionosphere electron density model. J Atmos Solar Terr Phys 70(15):1856-1862. https://doi.org/10.1016/j.jastp.2008.01.015
Nava B, Rodríguez-Zuluaga J, Alazo-Cuartas K, Kashcheyev A, Migoya-Orué Y, Radicella SM, Amory-Mazaudier C, Fleury R (2016) Middle- and lowlatitude ionosphere response to 2015 St. Patrick's Day geomagnetic storm. J Geophys Res Space Phys 121(4):3421-3438. https://doi.org/10. 1002/2015JA022299

Nose M, lyemori T, Sugiura M, Kamei T (2015) Geomagnetic Dst index. World Data Cent Geomagn Kyoto. https://doi.org/10.17593/14515-74000

Ohashi M, Hattori T, Kubo Y, Sugimoto S (2013) Multi-layer ionospheric VTEC estimation for GNSS positioning. Trans Inst Syst Control Inf Eng 26(1):16-24

Okoh DI, McKinnell L-A, Cilliers PJ (2010) Developing an ionospheric map for South Africa. Ann Geophys 28(7):1431-1439. https://doi.org/10.5194/ angeo-28-1431-2010

Olsen N, Friis-Christensen E, Floberghagen R, Alken P, Beggan CD, Chulliat A, Doornbos E, da Encarnao JT, Hamilton B, Hulot G, van Ijssel J, Kuvshinov A, Lesur V, Lhr H, Macmillan S, Maus S, Noja M, Olsen PEH, Park J, Plank G, Pthe C, Rauberg J, Ritter P, Rother M, Sabaka TJ, Schachtschneider R, Sirol $\mathrm{O}$, Stolle C, Thbault E, Thomson AW, Tffner-Clausen P, Velmsk L, Vigneron J, Visser P (2013) The Swarm satellite constellation application and research facility (SCARF) and Swarm data products. Earth Planets Space 65(11):1189-1200. https://doi.org/10.5047/eps.2013.07.001

Otsuka Y, Ogawa T, Saito A, Tsugawa T, Fukao S, Miyazaki S (2002) A new technique for mapping of total electron content using GPS network in Japan. Earth Planets Space 54(1):63-70. https://doi.org/10.1186/BF03352422

Prölss GW (1995) lonospheric F-region storms. In: Volland H (ed) Handbook of atmospheric electrodynamics, 2nd edn. CRC Press, Boca Raton

Raymund TD, Franke SJ, Yeh KC (1994) Ionospheric tomography: its limitations and reconstruction methods. J Atmos Terr Phys 56(5):637-657. https:// doi.org/10.1016/0021-9169(94)90104-X

Rius A, Ruffini G, Cucurull L (1997) Improving the vertical resolution of ionospheric tomography with GPS occultations. Geophys Res Lett 24(18):2291-2294. https://doi.org/10.1029/97GL52283

Rovira-Garcia A, Ibanez-Segura D, Orus-Perez R, Juan JM, Sanz J, Gonzalez-Casado $G$ (2020) Assessing the quality of ionospheric models through GNSS positioning error: methodology and results. GPS Solut 24(1):1-12. https:// doi.org/10.1007/s10291-019-0918-z

Saito A, Miyazaki S, Fukao S (1998) High resolution mapping of TEC perturbations with the GSI GPS network over Japan. Geophys Res Lett 25(16):3079-3082. https://doi.org/10.1029/98GL52361

Saito S, Suzuki S, Yamamoto M, Saito A, Chen CH (2017) Real-time ionosphere monitoring by three-dimensional tomography over Japan. Navig J Inst Navig 64(4):495-504. https://doi.org/10.1002/navi.213

Saito S, Yamamoto M, Saito A, Chen, C. H., (2019) Real-time 3-D lonospheric tomography and its validation by the MU radar. In: 2019 URSI Asia-Pacific radio science conference (AP-RASC). IEEE (pp 1-1). https://doi.org/10. 23919/URSIAP-RASC.2019.8738382

Schmidt M, Bilitza D, Shum C, Zeilhofer C (2008) Regional 4D modeling of the ionospheric electron density. Adv Space Res 42(4):782-790. https://doi. org/10.1016/j.asr.2007.02.050

Seemala GK, Yamamoto M, Saito A, Chen C-H (2014) Three-dimensional GPS ionospheric tomography over Japan using constrained least squares. J Geophys Res Space Phys 119(4):3044-3052. https://doi.org/10.1002/ 2013JA019582

Shiokawa K, Otsuka Y, Ogawa T, Kawamura S, Yamamoto M, Fukao S, Nakamura T, Tsuda T, Balan N, Igarashi K, Lu G (2003) Thermospheric wind during a storm-time large-scale traveling ionospheric disturbance. J Geophys Res Space Phys 108(A12):1423. https://doi.org/10.1029/2003JA010001

Ssessanga N, Kim YH, Kim E (2015) Vertical structure of medium-scale traveling ionospheric disturbances (MSTIDs). Geophys Res Lett 42(21):9156-9165. https://doi.org/10.1002/2015GL066093

Ssessanga N, Yamamoto M, Saito S, Saito A, Nishioka M (2021) Complementing regional ground GNSS-STEC computerized ionospheric tomography (CIT) with ionosonde data assimilation. GPS Solut 25:93. https://doi.org/10. 1007/s10291-021-01133-y

Stankov SM, Warnant R (2009) lonospheric slab thickness-analysis, modelling and monitoring. Adv Space Res 44(11):1295-1303. https://doi.org/10. 1016/j.asr.2009.07.010

Tsagouri I, Belehaki A, Moraitis G, Mavromichalaki H (2000) Positive and negative ionospheric disturbances at middle latitudes during geomagnetic 
storms. Geophys Res Lett 27(21):3579-3582. https://doi.org/10.1029/ 2000GL003743

Tsai L-C, Liu C, Tsai W, Liu C (2002) Tomographic imaging of the ionosphere using the GPS/MET and NNSS data. J Atmos Solar Terr Phys 64(18):20032011. https://doi.org/10.1016/S1364-6826(02)00218-3

Wu X, Hu X, Gong X, Zhang X, Wang X (2009) Analysis of the inversion error of ionospheric occultation. GPS Solut 13(3):231-239. https://doi.org/10 1007/s10291-008-0116-X

Yasyukevich Y, Astafyeva E, Padokhin A, Ivanova V, Syrovatskii S, Podlesnyi A (2018) The 6 September 2017 X-class solar flares and their impacts on the ionosphere, GNSS, and HF radio wave propagation. Space Weather 16(8):1013-1027. https://doi.org/10.1029/2018SW001932
Yeh KC, Raymund TD (1991) Limitations of ionospheric imaging by tomography. Radio Sci 26(6):1361-1380. https://doi.org/10.1029/91RS01873

Yue X, Schreiner WS, Lei J, Sokolovskiy SV, Rocken C, Hunt DC, Kuo Y-H (2010) Error analysis of Abel retrieved electron density profiles from radiooccultation measurements. Ann Geophys 28(1):217-222. https://doi.org/ 10.5194/angeo-28-217-2010

\section{Publisher's Note}

Springer Nature remains neutral with regard to jurisdictional claims in published maps and institutional affiliations.

\section{Submit your manuscript to a SpringerOpen ${ }^{\circ}$ journal and benefit from:}

- Convenient online submission

- Rigorous peer review

- Open access: articles freely available online

- High visibility within the field

- Retaining the copyright to your article

Submit your next manuscript at $\boldsymbol{\nabla}$ springeropen.com 